\title{
The syntax of Tzotzil auxiliaries and directionals: the grammaticalization of "motion"
}

\author{
John B. Haviland \\ Reed College
}

The problem to be considered arises from the (Zinacantec) Tzotzil encoding of simple motion, which leads to a syntactic puzzle. The syntactic puzzle in turn leads back to the linguistic expression of motion and space, now understood as results of a process of grammaticalization.

Consider first a group of English words like up, above, ascend, climb, lift, and raise. There is clearly no etymological connection between them, although a semantic analysis might well try to connect their meanings in some systematic way. Perhaps, for example, the words would figure in a definitional circle: $u p$ captures some notion of vertical trajectory; ascend means 'go up'; raise means 'cause to ascend'; and so on. But there would be no MORPHOLOGICAL or GRAMMATICAL reasons to make these interconnections, and each word would deserve its own separate lexical entry.

Now consider, by contrast, the Tzotzil root muy. It gives rise to a number of lexical forms, of which those of interest are exemplified in (1-6). ${ }^{1}$

(1)-(3) illustrate the root as a normal intransitive verb stem. Like all main verbs in Tzotzil, it must be inflected for both aspect ( $c h$-marking incompletive, $l$ completive) and person. ( $i$ - is a 1st person absolutive prefix, and -otik is a 1st person inclusive plural absolutive suffix.)

(1) $\mathrm{CK}: 127$

ch-i-muy ta ba k'atal toj

ICP-1A-ascend PREP top sideways pine

I would climb up the leaning pines.

(2) $\mathrm{CK}: 127$

ch-i-muy j-tuch'i tajchuche

ICP-1A-ascend 1E-cut ART mushroom_sp.

I climbed up to pick the lentinus mushrooms.

(3) SSS: 91

1-i-muy- otik te yo'-e,

CP-1A-ascend-1PLINCL there where-CL

We went up there [on an observation tower].

In (2), the fully inflected intransitive verb chimuy 'I ascend' has what appears to be a purposive adjunct, $j$-tuch' $i$ tajchuche '(in order that) I cut mushrooms' where the transitive verb $j$-tuch' bears NO aspectual inflection but only person marking (here a 1st person ergative prefix with a presumed zero 3rd-person absolutive). The absence of aspectual inflection is characteristic of various purposive constructions in Tzotzil, and is normally labelled 'subjunctive'.2

(4) SSS: 91

muy
ascend (AUX) 1E-look-1PLINCL what
We went up to see how big Mexico City was. 
(5) \{constructed\}

ch- muy
ICP-ascend (AUX) eat-SUBJ-1A PREP head house
I will go up to eat in the attic.

(2) contrasts rather sharply with (4) and (5), which illustrate the use of muy as an AUXILIARY verb. Here the auxiliary itself is NOT inflected for person, though it bears aspectual affixes. (The bare form illustrated in 4 is understood as completive; 5 shows an incompletive prefix.) Following the auxiliary is again a 'subjunctive' verb, marked for person but not for aspect. (5) shows that when this second verb (which following Aissen 1993 I will call V2) is intransitive, it bears an explicit subjunctive suffix $-i k$. The auxiliary-V2 construction thus distributes the morphology of the simple Tzotzil verb over two different elements which are tightly bound together, being separable only by a small set of clitics. ${ }^{3}$ The auxiliary bears aspect, and V2 inflects for person. The combination auxiliary-V2 has been called a 'Motion-cum-purpose' construction (Aissen 1984, 1987:16) to reflect the characteristic gloss.

Finally, (6) illustrates a further DIRECTIONAL form derived from the same root muy by suffixing $-e l$.

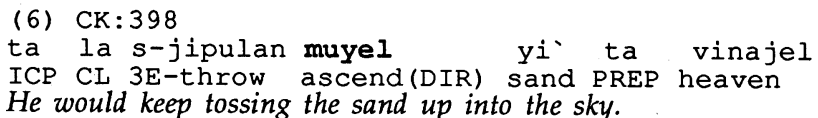

The directional closely follows a main verb as a kind of locative adverb. Here neither the verb jip 'throw' nor the all-purpose preposition ta 'at, on, to, from, etc.' conveys any information about the path involved. It is instead the directional muyel that expresses the upward trajectory.

By contrast with the English words mentioned at the outset which were SEMANTICALLY relatABLE but UNrelated at the level of morphology and syntax, it is clearly desirable to connect these different uses of the Tzotzil root muy. How must a lexical entry for this Tzotzil root be constructed so as to reflect the various syntactic guises it can assume and also their underlying commonality of meaning?

Muy 'ascend' is one of a small set of Tzotzil roots which display these different forms. All are ordinary intransitive verb roots, mostly verbs of 'motion'. The entire set of roots which produce AUXILIARY verbs is shown in (7), arranged into semantic classes that include deictically anchored motion, point-oriented motion, enclosure- or region-oriented motion, and motion on a vertical axis. 4 There are also two roots in the set with an aspectual meaning. 5

DIRECTIONALS are derived by suffixing -el to virtually the same verbal roots that yield auxiliaries. (In (7) those roots which produce only auxiliaries are shown in square brackets, and those which produce only directionals are shown in parentheses.) 
(7) Tzotzil auxiliary and directional roots

Deictically anchored motion $\mathrm{ba}(\mathrm{t})$ ' $\mathrm{go}$ ' (as directional "from time to time") tal 'come'

k'ot 'arrive there' yul 'arrive here'

Point-oriented motion

'ech' 'pass by' (as directional, 'away') sut 'return' kom 'stay'

(jelav 'pass by')

[a(y) 'go and return']

Enclosure or region oriented motion 'och 'enter'

lok' 'exit'

Vertical axis motion muy 'ascend'

yal 'descend'

Aspectuals

[laj 'finish']
(vay 'sleep')

lik 'arise, start'

All these roots directly produce intransitive verb stems, which in their ordinary incarnations require a syntactic subject, cross-indexed by an absolutive person affix. When the verb expresses motion, the subject in such cases (as in 1-3 above) is the entity in motion. However, in sentences like (4)-(6) there are no person markers attached to the forms of the motion-verb root. The syntactic puzzle posed by the use of these roots as auxiliaries and directionals is this: if the underlying roots are verbs of motion, who or what is doing the moving? How do we identify what Aissen (1993) calls the 'Mover'?

\section{Auxiliaries}

On first examination the motion associated with an auxiliary verb patterns as if the logical subject of the auxiliary motion verb were coreferential with the $S$ (intransitive subject) or A (transitive subject) argument of V2. Such a pattern is parallel to an example like (2) where the motion verb--not an auxiliary--IS inflected for person.

When V2 is intransitive, it has only a subject argument which seems naturally to be associated with the auxiliary's motion (or lack of motion in the case of kom 'stay'). Thus, in (5), the 'I' who will eat in the attic (shown by a 1st person ABSOLUTIVE suffix -on) is the ' $I$ ' who will go up to the attic. (8) and (9) are further examples with auxiliaries 'stay' and 'arrive (there)'.

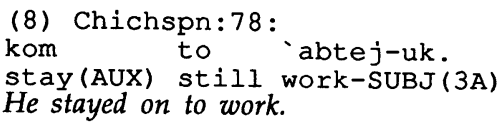

(9) T130:329

naka xa la ch-k'ot cham-uk z-na.

just already QUOT ICP-arrive (AUX) die-SUBJ(3A) PREP+3E-house

She just reached home and died. (Laughlin 1977:318)

In these cases there seems to be both a causal and a temporal link between the motion encoded in the auxiliary and the action of the main verb: a protagonist's action follows (or is contemporary with) a preparatory (if not literally purposive) motion by the same protagonist. 
When V2 is transitive, again its subject (or agentive argument) appears to be associated with the motion of the auxiliary. In (4) above, 'we'--the people crossindexed by the 1st person plural inclusive ERGATIVE affixes on the verb 'look'--are the ones who ascend.

Auxiliary constructions can also appear in the imperative, as in (10). The auxiliary element bears a zero aspectual affix, and V2 shows normal morphology for a transitive imperative.

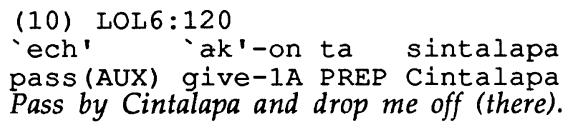

The logical subject or A argument of V2 (in this case an unstated 2nd person) is also understood to be the Mover.

Such facts seem to provide evidence for a Nominative/Accusative style Subject relation in Tzotzil, despite the ergative/absolutive agreement morphology. This result would coincide with an intuitive view of the purposive relation between the motion encoded by an auxiliary, and a 'goal' or 'purpose' described in V2. Here some willing agent moves (and the motion is encoded in an auxiliary) in order to bring about some intentional result (captured by V2). Corresponding claims have been advanced about some sister Mayan languages and their ancestors. ${ }^{6}$

However, a more careful look at the behavior of auxiliaries suggests that interpreting the motion denoted by the auxiliary cannot be strictly a syntactic matter. One sort of evidence is provided by examples in which V2 is passive. The details of such constructions are too complex to describe here, ${ }^{7}$ but (11) will illustrate the problem. One passive form that appears with auxiliaries has the suffix -el and bears formally ergative prefixes that cross-index the logical PATIENT.

(11) T84.TXT:226:

tal- em $k-i k^{\prime}-e l$ z- na 'a li rey come (AUX) -STAT 1E-take-PASS PREP+3E-house PT ART king

They've come to take us to the King's house. (CK:208).

An example like (11) is difficult to gloss; it means something along the lines of 'there is coming for us to be taken to the King's house'. Laughlin's translation indicates that the Mover--the entity that 'comes'--is understood as an indefinite 'they', which appears neither in the sentence nor, indeed, in the surrounding discourse. The 'we' who are to be taken have not 'come' anywhere, since we were already there. (The root tal denotes motion towards 'here', the speaker's deictic center.)

A simpler non-passive case appears in (12):

(12) T109:116

ba nox ech'-uk ak'ubal yo'-e

go(AUX) only pass-SUBJ(3A) night there-CL.

Just go spend the night there. (CK:82)

Here the auxiliary bears no overt aspect marker, and the overall construction must be interpreted as imperative. The preceding context makes clear that the ADDRESSEE is meant to be the one to go [to a graveyard]. The V2 involves an idiomatic expression $e c h^{\prime}$ ak'ubal 'lit., the night passes'. A person who, in 
English, would 'spend a night' can appear in such an idiom only as an oblique argument introduced by the relational noun - $u$ 'un.

(13) \{constructed\}

vokol $i$-0-'ech' $k$ - u'un ak'ubal

difficult CP-3A-pass 1E-ABIL night

I had $a$ hard night. (Lit., I managed with difficulty for the night to pass.)

There appears to be no argument of V2 in (12) which can provide a logical subject to the auxiliary $b a$ 'go'.

A similar problem arises with example (14).

(14) MONOL : 3 :

$\begin{array}{lll}\text { ch-ba } & \text { lok'-uk } & \text { 'akta noxtok } \\ \text { ICP-go(AUX) exit-SUBJ (3A) document too }\end{array}$

(We) will go to have a document issued also.

The free translation here obscures the problem, for the original Tzotzil sentence has no 'we'. The sentence

(15) \{constructed\}

ch-0-lok' akta

ICP-3A-exit document

A document will come out (i.e., be issued).

shows an expression used to describe the issuing of a signed, written declaration which often serves to settle civil grievances in Zinacantán. The sentence is intransitive, akta being the grammatical subject of the intransitive verb lok' 'exit'. However, it is clearly not possible for such a document first to go (to the townhall, in this case), in order then to be created and issued. It is the complainants who do the going, with the issuing of the akta the proposed result. This is made clear by the wider conversational context in (16): a man describes his continuing disputes with a relative, and how they ultimately went to the magistrate for settlement.

(16) MONOL :

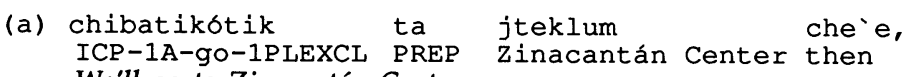
We'll go to Zinacantán Center.

(b) ch-ba j-k'opon-tikótik preserente ICP-go(AUX) 1E-talk_to-1PLE president We'll go to talk to the (municipal) president.

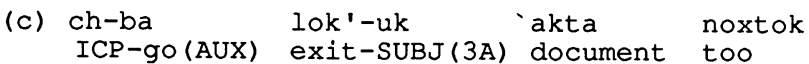
(We) will go to have a document issued also.

The sense of the auxiliary paired with $l o k^{\prime}$ in $(16 c)$ derives in part from the auxiliary $b a$ occurring in the previous sentence (16b), which has a transitive V2 (- $k^{\prime}$ opon 'talk to'). The DISPUTANTS will go to have the akta issued. The fact remains, however, that there is no argument available in $(14)(=16 \mathrm{c})$ which can correspond to the 'logical subject' of the auxiliary verb 'go'.

(17) is a last example. As I was about to leave Chiapas, a Zinacantec promised to repay a loan when I returned: 
(17) PV0 492

ja' to ch-(y)ul $k-a k^{\prime}-b-$ ot

! still ICP-arrive here 1E-give-BEN-2A

Just then I will give it to you arriving here.

If the Mover involved in the auxiliary $y u l$ 'arrive here (i.e., in this case, to the Chiapas village)' must co-refer with the ergative argument of the V2, (17) would have meant that this Zinacantec, not I, would be leaving the village to return sometime in the future--the exact reverse of the actual situation. It is almost as though the speaker is transposing himself (Haviland 1991b) into my shoes, to say in effect: 'you have only to arrive here for me to repay you'. But now the understood Mover corresponds to the object of V2.

Aissen $(1992,1993)$ uses such facts to motivate a syntactic account of Tzotzil auxiliaries in which the auxiliary is the functional head of a VP, selecting for a subjunctively marker complement clause, but in which the auxiliary has no nominal arguments, in particular no subject. Thus in a sentence like (2) muy functions as a normal intransitive verb with a cross-indexed subject, whereas in (4)(5) muy is an auxiliary which cannot have its own subject, imparting instead only its idealized spatial trajectory to the resulting purposeful action. The auxiliary thus represents a GRAMMATICALIZATION of the parent verbal root: it loses its ability to have a nominal argument, and it may, as I will argue briefly at the end of the paper, undergo both semantic generalization and formal erosion.

The Mover in an auxiliary construction is the entity that proposes, or is in a position to bring about the result expressed in V2. The auxiliary conjures a scene, in interaction with the wider discursive context, and motion must be assigned to arguments (explicit or implicit) by inference rather than by syntax. What pragmatic parameters operate to allow the combination of understood motion, coded in an auxiliary, with a purposive result coded as V2 requires further investigation.

\section{Directionals}

The same verb roots from which Tzotzil auxiliaries derive provide the source for the separate class of directionals, illustrated in (6) above. Unlike the auxiliary, which comes at the beginning of the verb complex and inflects for aspect, directionals immediately follow the main verb and are free of inflection, verbal or otherwise. Indeed, multiple directionals can be combined in a single Tzotzil sentence.

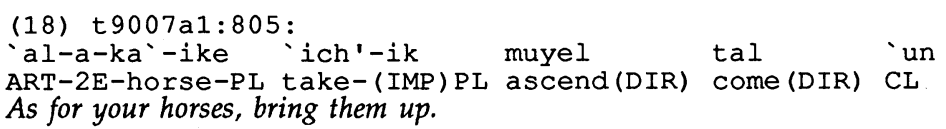

In (19) the combination of a main verb of motion (the transitive -otes 'insert' derived from 'och 'enter') with the motion directional tal 'coming' and the aspectual batel 'now and then' requires an idiomatic English translation that mixes motion and deictic elements in a way strikingly different from the Tzotzil.

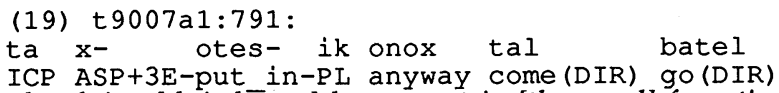

They bring [their horses] here to put in [the corral] from time to time. 
There is an apparent layering of the different categories, with the deictic directionals $t a l(e l)$ and 'ech'el following all other directionals except the aspectuals. The ideal ordering seems to be as in (20):

(20)

\begin{tabular}{|c|c|c|c|c|}
\hline $\begin{array}{l}\text { ENCL. } \\
\text { ochel } \\
\text { lok'el }\end{array}$ & (jelavel) $^{8}$ & $\begin{array}{l}\text { VERT. } \\
\text { muyel } \\
\text { yalel }\end{array}$ & (komel) & $\begin{array}{l}\text { DEIC. } \\
\text { ech'el } \\
\text { tal } \\
\text { (k'otel) } \\
\text { (yulel) }\end{array}$ \\
\hline
\end{tabular}

If a directional particle can be construed as a reduced reflex of its parent motion verb, we can ask, as we did with auxiliaries, how to construe its putative logical subject? In (6) it is the sand which ascends towards heaven. (21)-(24) show further directionals in action.
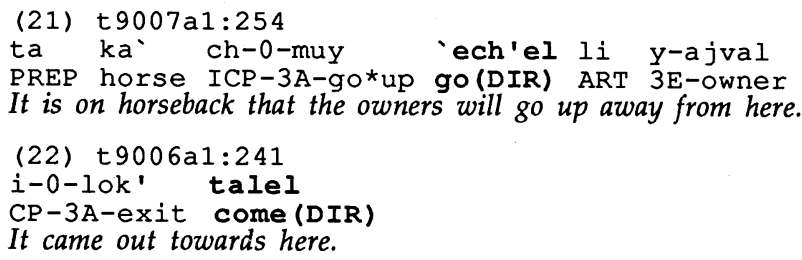

(23) LOL1:807:

ta j-k'an sutel noxtok ti j-pasajel 'une

ICP 1E-want return(DIR) again ART 1E-fare CL

$I$ (would) ask for my fare-money back again.

(24) LOL6:309:

ta j-nak' komel

ICP 1E-hide stay (DIR)

I would hide it away [equipment left at a distant market].

In these cases there is an apparent association between the directional and the Absolutive argument of the main verb: either the S(ubject) of an intransitive main verb (the ascending or exiting entities in (21) and (22)), or the $\mathrm{O}$ (bject) of a transitive main verb (the fare returned in (23) or the hidden equipment left behind in (24)). Even with passive main verbs, the syntactic S--the logical patient--is clearly understood to be following the trajectory of the motion encoded in the directional.

(25) T154:198

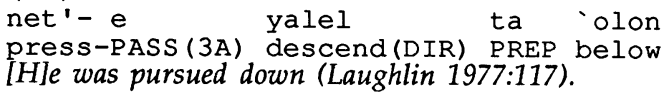

Once again, such a pattern has been claimed to obtain for analogous constructions in sister languages. In classical Quiché, for example, according to Dürr (1990:4), '[i]n transitive sentences [directionals] indicate the direction of the patient in accordance with the general ergative pattern of the language' ${ }^{9}$ An alternative formulation would associate the motion of the directional with that argument of the main verb occupying some sort of 'Theme' semantic role: an entity construed as moving or changing. 
However, this putative syntactic characterization also fails in Tzotzil. Consider first directionals with derived antipassives. From most transitive verb stems in Tzotzil it is possible to derive an intransitive stem by suffixing -van. Typically, if the transitive stem fits in the frame ' $\mathrm{X}$ does $\mathrm{Y}$ to $\mathrm{Z}$ ' the suffixed -van form fits in a corresponding intransitive antipassive frame ' $\mathrm{X}$ does $\mathrm{Y}$-ing (typically to people)'. Hence, from the transitive -toj 'pay for' one derives the intransitive tojvan- 'pay for someone (e.g., pay a salary or a brideprice)'. (26b) shows what happens when intransitive verb stems in -van co-occur with directionals.

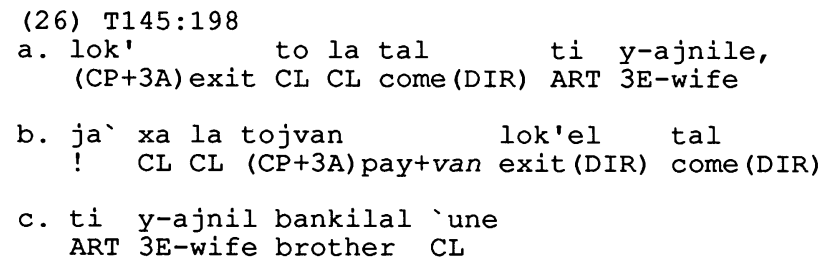

(a.) [The other one] got a wife. (c) The wife of the older brother (b) paid [the bride price] (Laughlin 1979: 195-6). Literally (jbh): (a) [the other one's] bride came out to here. (c) The wife of the older brother (b) paid [for the new bride's] coming out.

The story concerns a man who managed to get a bride only through the good offices of his older brother's wife. In clause (a) we are told that he got the bride (she 'exited' 'coming'); in lines (b) and (c), which form a single clause, we learn that the sister-in-law 'paid for [the new bride]', also with directionals 'exiting' and 'coming'. Here, the Mover who 'exits' her old house and 'comes' to her new husband's compound is the underlying, but syntactically unexpressed (or lexically incorporated), logical patient of the intransitive main verb tojvan 'pay [brideprice] for someone'. But this bride corresponds to no argument in the sentence.

Such examples suggest that the motion implied by directionals is also a matter of inference and not of syntax, that directionals like auxiliaries have no nominal arguments. The motion or trajectory is encoded as an adverbial augmentation of the scene described in the overall clause. Such an analysis seems especially pressing when we turn to examples in which the verb modified by directionals contains no hint of motion in its ordinary meaning. In such cases, the presence of directionals INJECTS motion into the action portrayed, and the resulting inferred trajectory must be attributed to elements which find no overt linguistic expression.

With verbs of speaking and perception, directionals can impose an orientation, both deictic and non-deictic, on a scene, with no suggestion of a literal moving argument.

(27) anvask4:96:

ja' taj lo'il i-y-a'i tal ta s-na
! DEM gossip CP-3E-hear come (DIR) PREP 3E-house

That's the gossip that he heard at his house.

In (27) the deictic tal 'coming' transposes the perspective adopted by the speaker onto that of the receiver of words: the gossip came HERE to him. In (28) the directional adds an upward trajectory to the looking. 
(28) T152:62:

$x i$ ta j-k'el muyel 'une

thus ICP 1E-look ascend(DIR) CL

I was looking up (Laughlin 1977: 202).

With other sorts of main verbs more inferential ingenuity is required to construe the meaning of the directional. (29) exhibits the directional komel 'staying' whose non-motion must accrue to the object of the main verb 'burn' (here a cornfield).

(29) T162:196

j-chik' xa komel

$1 \mathrm{E}$-burn CL stay (DIR)

I've burned it (Laughlin 1977: 390).

This line is spoken by a lazy husband after he has gone home after burning off fields in preparation for planting. The directional komel implicates the fact that the man himself is no longer in the fields (they 'stayed behind', after he departed), and that he has finished burning them. The overall effect of the directional is thus partly aspectual.

Further varieties of motion are implied in (30)-(34), all of which have the directional tal 'coming'.

(30) T61:234:

$\begin{array}{ll}\text { t'om } & \text { tal volkan } \\ \text { (CP }+3 A) \text { explode DIR } & \text { volcano }\end{array}$

The volcano erupted [and then its ashes] came.

(31) LOL1:875:

ta j-ch'ak tal j-pasajeb 'une

ICP 1E-divide DIR 1E-fare CL

I will separate out (from the rest of the money) my bus fare

[before bringing my money back homel.

(32) BARIL:175:

1-i-laj tal un

CP-1A-finish DIR CL

I was injured [on my way back here].

(33) t9007a1:988:

mi ja' lek ch-a-ve'-ik tal che'e?

\&! good ICP-2A-eat-PL DIR PT

Should you then eat [before you come here]?

(34) T86:352:

mi'n a-toj tal a-ka?

Q 2E-pay DIR 2E-horse

"Did you pay for your mule [before bringing it back herel? (Laughlin 1977: 284).

One common element in all these inferred trajectories is that the action of the main verb takes place either BEFORE or SIMULTANEOUSLY with the motion implied in the directional. (For example, in (33) the question suggests that the addressee should eat first and come here afterwards.) Apart from such a temporal sequence, though, there is rather little consistent patterning. The directional depends on the overall scene evoked by the verb and the rest of the context of situation to supply a Mover.

Directionals can also accompany stative adjectival predicates. De León (1991) reports the frequent use of egocentrically anchored directionals combined with positional adjectives in an experimental interactive game in which Zinacantecs 
offered verbal descriptions of photographs. (35) is an example from de León's transcripts.

(35) tape2a1:26

cha' kot ich j-moj cholol ech'el

two NC chile one-blow lined_up(+3A) pass(DIR)

(These are) two chiles lined up [pointing away from me].

Similar examples abound in conversational and textual materials.

(36) LOL3: 921

ja' tey tzakal ech'el $\mathrm{x}$-chi'uk
$!$ there joined pass (DIR)
It [went awayl attached to him.

(37) $\mathrm{T} 75: 53$

chukul komel ta te'el alampre

tied up (+3A) stay(DIR) PREP post wire

[He had] left [the cow] tied to the fence post (Laughlin 1977: 228).

Directionals also accompany non-verbal expressions of location. These may be formed with 'relational nouns' (which denote parts or regions of their grammatical possessors).

(38) T9006a1:46:

y-ak'ol tal Nachij

3E-above come(DIR) place name

(It is) above Nachij on this side (i.e., above coming).

More surprising, perhaps, is the use of the directionals tal and 'ech'el to modify ordinary locative phrases of the form PREPOSITION+NP.

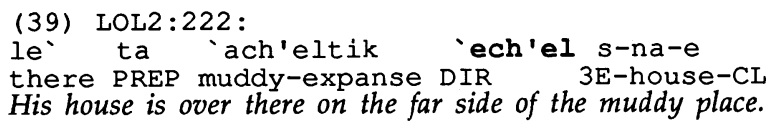

Here a whole scene is broken into deictic, locational, and trajectory elements by the Tzotzil syntax. There is first a distal demonstrative le 'there' (which also serves as the predicate that can bear absolutive suffixes, in this case a zero third person). It is complemented by a prepositional phrase, whose preposition $t a$ is semantically empty, 'at/near/in a muddy place'. The directional 'ech'el in turn suggests the image of, say, walking from the muddy place in a direction away from 'here'. The same scene must be rather more statically re-packaged in the English translation.

In both the auxiliary and directional cases, then, inference rather than syntax assigns putative logical arguments to the underlying (or perhaps 'fictive' [Talmy 1985]) motion expressed. This suggests that the auxiliary and directional uses of a root like muy are no longer fully verbal: the argument structure available to muy as a motion verb has been eroded away from muy the auxiliary (although it is still enough of a verb to carry aspect) and still more from muyel the directional which now involves only schematic motion, direction, or orientation.

\section{AUX + DIR}

Despite differences in detail, auxiliaries and directionals are formed from the same motion roots. How do the two slots combine? 
First, we have seen that there is an association between the motion of the auxiliary and an understood (though possibly unexpressed) purposive agent in the overall action. Similarly, we have seen that the directional specifies a trajectory that is construed as simultaneous with or subsequent to the action of the main verb. The ordering of auxiliary and directional also suggests iconically the temporal sequencing of the two different phases of motion: the motion of the auxiliary comes first, that of the directional afterwards. Thus, apparently redundant combinations of semantically equivalent auxiliary and directional can be understood to have nonredundant force.

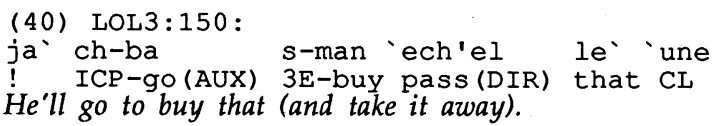

In (40) $b a$ 'go (AUX)' is paired with 'ech'el 'going (DIR)'. The sequence implied is: 'he goes to buy [and afterwards take away] that thing'.

The combination of auxiliary and directional is thus perfectly designed to encode a ROUND-TRIP.

(41) LOL $4: 143$ :

ch-ba tal j-sa k-ikatz ta jobele ICP-go (AUX) 1E-search*for come (DIR) 1E-cargo PREP San_Cristóbal

I'll go to find my goods in San Cristóbal (and bring them back here).

Moreover, since two sorts of motion or trajectory can be grammatically incorporated into every verb phrase by using both auxiliary and directional positions, the main verbs themselves can be lexically specific, and the overall topology of an action can still be economically encoded. The lexicalized character of the main verb is also, thereby, distributed over the entire scene--the action and both its preparatory and resulting paths. Thus consider the distribution of the action of 'grabbing' in (42).

(42) LOL1:348:

pinchi alvanil ba s-tzak-on 'ochel

damned mason go (AUX) 3E-grab-1A enter(DIR)

The damned mason just went and grabbed me [and hauled me] inside.

\section{The grammaticalization of motion}

Heine (1992:40-44) proposes a Motion schema--'X moves to/from Y'--as one starting point for a grammaticalization chain in which a verb evolves into a tense/aspect marker (TAM). An auxiliary, on Heine's account, is simply 'a linguistic item covering some range of uses along' (1992:93) such a chain. The grammaticalization process comprises a sequence of diagnostic linguistic shifts that include desemanticization, decategorialization, cliticization, and erosion (68ff.). For each shift, Heine posits an 'Overlap model' that involves a three step progression from a source stage to a target stage, with an intermediate stage where constructions are ambiguous between the source and target patterns (66ff.).

Recent work by Zavala (1992) and Craig (1992) explores the grammaticalization of auxiliary and directional elements in a Mayan comparative context in considerably more detail than can be accommodated here. Tzotzil auxiliaries and directionals are clearly consistent with Heine's scheme, falling near 
the start of the chain when compared with, say, Akatek (Zavala 1992) or Sakapultek (du Bois 1992) auxiliaries or Mam post-verbal directionals (England 1976). How do we understand the synchronic grammatical categories that result from such a putative grammaticalization process?

1. Erosion

The verbal roots that give rise to AUX and DIR elements show incipient phonological reduction of a characteristic kind. Thus bat 'go' frequently appears as AUX $b a$, and ' $a y$ 'go and return' yields AUX ' $a .10$ Similarly, the suffixed DIR talel 'coming' is often shortened to tal; moreover, where Zinacantec Tzotzil has directionals 'ech'el 'passing, away' and batel 'going, from time to time', nearby Chenalho Tzotzil uses 'el and bel.11

2. Decategorialization and cliticization

AUX and DIR elements are formally unlike verbs despite their verbal provenance. The results of decategorialization have been the primary focus here: for example, the Mover is not a syntactically governed argument of AUX and DIR elements. AUX and DIR also have restricted clitic-like positions of occurrence around a main verb (or other predicate).

The same roots that produce AUX and DIR elements also give rise to normal intransitive verbs. Synchronic lexical rules must thus specify that from a root like muy one can produce both a lexical verb and an auxiliary, differing minimally as lexical vs. functional heads of VPs, along lines suggested by Aissen (1993). The DIR arises from still more severe decategorialization, since it functions as an adverbial enclitic. How exactly to represent such lexical relations and the grammatical categories expressed by a single underlying root is a problem still to be resolved.

3. Conceptual generalization.

Although as full lexical verbs, the roots in question are often extended to a variety of metaphorical or non-motion senses, 12 as auxiliaries their meanings are highly schematized, limited to the sorts of trajectories and paths (Talmy 1985) expressed by closed class grammatical elements in other languages (for example, English verbal particles and prepositions).

The sense of literal motion may be generalized onto non-spatial domains in characteristic and familiar ways. For example, the auxiliary $b a(t)$ 'go' in the incompletive aspect can have a clear future meaning, as in (43).

\section{(43) CHID:27:}

$\begin{array}{lll}\text { j-tak ta k'anele, yu'un ch-ba } & \text { tal-uk } \\ \text { lE-send PREP wanting because ICP-go (AUX) } & \text { come-SUBJ (+3A) } \\ \text { (However much [liquor]) I send for, it's going to come. }\end{array}$

Given the mutually inconsistent meanings of bat 'go' and tal 'come' as MOTION verbs the only apparently possible reading of the auxiliary construction $c h$-ba tal-uk is, as in the idiomatic English translation, 'it's going to (i.e., will) come'. Bat thus stands at a rather standard point along the path from motion verb to tense/aspect marker.

As an extension of the Tzotzil aspect system, auxiliaries exceptionally combine with predicates which without auxiliaries could NOT bear aspect directly at all. (44) shows that surface adjectives which derive from 'positional' roots (see Haviland 1992) can combine with auxiliary verbs. ${ }^{13}$ Uniquely, such normally stative predicates can in an auxiliary construction bear aspect. 
(44) $\mathrm{T} 83: 32$

$\begin{array}{lll}\text { ch-tal } & \text { chotl-ik-on ta y-olon } & \text { one } \\ \text { ICP-come (AUX) sitting-SUBJ-1A PREP 3E-underneath avocado } \\ \text { I'm coming to sit under the avocado tree. (CK:197) }\end{array}$

Such a construction is possible with positional adjectives denoting normal human positions (e.g., va 'al 'standing', puch'ul 'lying prone', even nakal 'at home, residing') when the subject argument can be construed as a volitional agent.

With DIR elements, there are also semantic shifts and reanalyses. For example, the DIR batel, which should mean 'away, going' (and DOES mean exactly this in neighboring Tzotzil dialects) in Zinacantán has come to have more of an aspectual flavor: 'from time to time'. In its place 'ech'el 'passing' has been recruited to fill the deictic 'away from here' slot in the directional paradigm (as in (21), (36), (39), (40)).

Nonetheless, such shifts do not simply represent a dogged progression towards a TAM target, bleached of motion entirely. The highly schematized trajectories or paths encoded in AUX and DIR elements seem to be a target in themselves. Thus the gap left by reinterpreting 'ech'el is in turn refilled by inventing the otherwise idiosyncratic DIR jelavel 'passing'. ${ }^{14}$

Here Tzotzil and, indeed, languages across the Mayan family represent a minor challenge or addition to Heine's view of auxiliaries as necessarily involving a progression from Verb to TAM. Mayan languages seem to use AUX constructions to encode not only tense and aspect, but also path and trajectory. They use auxiliaries and directionals to build space directly, as it were, into grammar.

1 Except where noted, examples are drawn from recorded conversations or from Tzotzil texts published in Laughlin 1977 (abbreviated as CK), or Laughlin 1980 (abbreviated SSS).

2 See Haviland (1981), pp. 224-227, Aissen (1987), pp. 15-18, 214-229, and Aissen (1993), sect. 2.1, for Tzotzil 'subjunctive' form and usage. Aissen (1993) bases much of her argument about the syntax of auxiliary constructions on parallels with a causative construction in which a fully inflected form of $a k^{\prime}$ 'cause' combines with a dependent clause whose verb exhibits the same subjunctive morphology. Also involving subjunctive form are desiderative constructions with chak 'want' or -o 'on-uk 'would like'.

3 In recent work, Judith Aissen $(1992,1993)$ proposes a syntactic account of why the morphology is distributed in exactly the way it is, though that will not be a direct concern here.

4 The classification is presented in Haviland 1991a.

5 The root lik can mean both 'arise' and 'start'.

6 For example, Dürr (1990) states that in classical Quiché motion auxiliaries when combined with a transitive main verb 'indicate the movement of the agent, contrary to the general ergative pattern' of the language.

7 More detailed argument about passive V2s is given in Haviland 1991a:16-19, and especially Aissen 1984, 1993.

8 The positions of jelavel and other parenthesized directionals in this table are provisional.

9 Similarly, Craig (1979:37) argues that cardinal directionals in Jakaltek 'express the movement of the actor/subject' with intransitive main verbs but with transitive 
verbs 'refer to the movement of the object/patient'. Jakaltek deictic directionals 'toward/away' are calculated from the perspective of the actor/subject. In languages with more highly schematized directionals, no obvious pattern of association is evident. See, e.g., England 1976 on Mam.

10 Indeed, in the neighboring Tzotzil dialect of Chamula, the apparent AUX la(j) 'finish' now functions as the completive prefix in the normal verb paradigm.

11 Aissen (1993) points out that the CV shape of the reduced auxiliaries is quasicanonical for functional elements in the language, so that the apparent phonological erosion has a kind of phonotactic target.

12 Consider, for example, the extended meanings of 'ech' 'pass' and lok' 'exit' as main verbs in (12) and (14). See Haviland 1991a:43-55 for further semantic details.

13 Such cases in which the complement selected by the auxiliary is not (formally) a verb at all represent a problem for Aissen's (1993) analysis of auxiliaries as functional heads in which, following Abney 1987, she takes it as a defining characteristic of functional heads that they select unique complement types. Positional predicate adjectives cannot ordinarily bear aspect, although they do have a number of verb-like properties (see Haviland 1992). Note that AUX is NOT possible with fully verbal stems derived from such roots.

14 This form is unique in both phonological shape and lexical provenance, since it is the only directional derived from a disyllabic stem, and indeed, from a DERIVED stem formed by suffixing an intransitivizer - $a v$ to the root jel 'change, exchange'.

\section{References}

Abney, Stephen. 1987. The English noun phrase in its sentential aspect. Unpublished Ph.D. dissertation. MIT.

Aissen, Judith L. 1984. Control and command in Tzotzil purpose clauses. Proceedings of the Tenth Annual Meeting of the Berkeley Linguistics Society, 559-571.

Aissen, Judith L. 1987. Tzotzil Clause Structure. Dordrecht: Reidel.

Aissen, Judith L. 1992. Tzotzil auxiliaries of motion. Paper presented at the 91st Annual Meetings of the American Anthropological Association, San Francisco, Dec. 1992.

Aissen, Judith L. 1993. Tzotzil auxiliaries and related constructions. Ms.

Craig, Colette. 1979. Jacaltec, field work in Guatemala. Languages and Their Speakers, ed. by Timothy Shopen, 3-57. Cambridge, Ma.: Winthrop.

Craig, Colette. 1992. Grammaticalization of space in Mayan: Jakaltek directionals in family perspective. Ms.

Dürr, Michael. 1990. Reference to space in colonial Quiché. Función, 1989-90, Universidad de Guadalajara, Jalisco, México.

de León, Lourdes. 1991. Space games in Tzotzil: creating a context for spatial reference. Working paper no. 4, Cognitive Anthropology Research Group, MPI for Psycholinguistics, Nijmegen, The Netherlands.

du Bois, John W. 1992. Topographical strategies for topic management in Sakapulteko Maya. Paper presented to the 91st Annual Meetings of the American Anthropological Association, San Francisco, Dec. 1992. 
England, Nora C. 1976. Mam directionals and verb semantics. Mayan Linguistics I, ed. by Marlys McClaren, 202-211. UCLA, American Indian Studies Center.

Haviland, John B. 1981. Sk'op sotz'leb: el tzotzil de San Lorenzo Zinacantán. Mexico City: Universidad Nacional Autónoma de México.

Haviland, John B. 1991a. The grammaticalization of motion (and time) in Tzotzil. Working paper \#2, Cognitive Anthropology Research Group at the Max Planck Institute for Psycholinguistics.

Haviland, John B. 1991b. Projections, transpositions, and relativity . Paper prepared for Wenner-Gren conference on Rethinking Linguistic relativity, Ocho Rios, May 3-11, 1991. Working Paper: Cognitive Anthropology Research Group, Nijmegen.

Haviland, John B. 1992. Seated and settled: Tzotzil verbs of the body. Zeit. Phonetik, Sprachwissenschaft und Kommunikationsforschung 45.543-561.

Heine, B. 1992. Auxiliaries. Ms.

Laughlin, Robert M. 1977. Of cabbages and kings, tales from Zinacantán. Washington, D.C.: Smithsonian.

Laughlin, Robert M. 1980. Of shoes and ships and sealing wax, sundries from Zinacantán. Washington, D.C.: Smithsonian.

Talmy, Leonard. 1985. Lexicalization patterns: semantic structure in lexical forms. Language typology and syntactic description, Vol 3, ed. by Timothy Shopen, 57-149. London: Cambridge University Press

Zavala Maldonado, Roberto. 1992. Mayan directionals: patterns of grammaticalization. Paper presented at the 91 st Annual Meetings of the American Anthropological Association, San Francisco, Dec. 1992 . 